\title{
Obstetric anal sphincter injury in adolescent mothers
}

Henry H. Chill ${ }^{1,2^{*+}}$, Michal Lipschuetz ${ }^{2+}$, Eyal Atias², Tzvika Shimonovitz ${ }^{2}$, David Shveiky ${ }^{1,2}$ and Gilad Karavani ${ }^{2}$

\begin{abstract}
Background: Obstetric anal sphincter injury (OASI) is a debilitating complication of vaginal delivery which has yet to receive ample attention in adolescents. The aim of this study was to describe risk for OASI in adolescent mothers compared to adults. We further attempted to compare risk factors for OASI between these two age groups.

Methods: We performed a retrospective cohort study between 2003 and 2019. Primiparous women who delivered vaginally, 21 years and younger were compared to women ages 26-35. Excluded were preterm, multifetal, nonvertex, cesarean deliveries as well as intrauterine fetal death. Rate of OASI as well as obstetric and labor characteristics of women with OASI, were compared between groups. Finally, risk factors were assessed for each group separately. Univariate and multivariate logistic regression model were performed.
\end{abstract}

Results: Final analysis was performed on 5113 nulliparous adolescents and 13,845 nulliparous in the 26-35 age group. Allocation to study groups was according to OASI - Sixty-seven adolescents (1.3\%) had a 3rd or 4th degree perineal tear and were defined as the OASI group, while 5046 patients (98.7\%) did not have such a tear. In the adult group, 199 out of 13,845 patients (1.4\%) were diagnosed with OASI. Occurrence of OASI did not differ between groups $(p=0.510)$. Comparison of women with OASI in the adolescent group vs. adult group found differences with regard to operative vaginal delivery, $(20.9 \%$ vs. $36.2 \%$, respectively; $p=0.023)$ and meconium stained amniotic fluid (9.1\% vs. $21.3 \%$, respectively; $p=0.027$ ).

Following multivariate analysis the only parameter independently associated with OASI in the adolescent age group was head circumference $\geq 90$ th percentile with an adjusted odds ratio of $3.08(\mathrm{Cl} 1.48-6.38, p=0.003)$. In the adult group the similar analysis revealed operative vaginal delivery $(\mathrm{OR}=2.44, \mathrm{Cl} 1.72-3.47, p<0.001)$ and a birthweight $\geq 90$ th percentile $(\mathrm{OR}=2.23, \mathrm{Cl} 1.19-4.18, p=0.012)$ to be independent risk factors for OASI.

Conclusion: Adolescents have similar risk for OASI compared to adults but differ in risk factors leading to OASI. Head circumference $\geq 90$ th percentile was found to be associated with OASI in this age group.

Keywords: Perineal lacerations, Adolescent pregnancy, Vaginal tears, Obstetric anal sphincter injury

\footnotetext{
* Correspondence: henchill@gmail.com

${ }^{\dagger}$ Henry H. Chill and Michal Lipschuetz contributed equally to this work.

'Division of Female Pelvic Medicine and Reconstructive Surgery, Department of Obstetrics and Gynecology, Hadassah Medical Organization and Faculty of Medicine, Hebrew University of Jerusalem, Jerusalem, Israel

${ }^{2}$ Division of Obstetrics and Gynecology, Hadassah Medical Organization and

Faculty of Medicine, Hebrew University of Jerusalem, Jerusalem, Israel
}

(c) The Author(s). 2021 Open Access This article is licensed under a Creative Commons Attribution 4.0 International License, which permits use, sharing, adaptation, distribution and reproduction in any medium or format, as long as you give appropriate credit to the original author(s) and the source, provide a link to the Creative Commons licence, and indicate if changes were made. The images or other third party material in this article are included in the article's Creative Commons licence, unless indicated otherwise in a credit line to the material. If material is not included in the article's Creative Commons licence and your intended use is not permitted by statutory regulation or exceeds the permitted use, you will need to obtain permission directly from the copyright holder. To view a copy of this licence, visit http://creativecommons.org/licenses/by/4.0/. The Creative Commons Public Domain Dedication waiver (http://creativecommons.org/publicdomain/zero/1.0/) applies to the data made available in this article, unless otherwise stated in a credit line to the data. 


\section{Background}

Adolescent pregnancy is a phenomenon estimated to occur in $13 \%$ of women in the United States and $25 \%$ worldwide $[1,2]$. Though steadily declining over the past decade, the impact of adolescent pregnancies on health outcomes is too significant to go overlooked [3]. Currently, complications during pregnancy and childbirth are the second leading cause of mortality in the 15 to 19-year-old age group worldwide [4].

Several studies have presented outcomes of pregnancy in adolescent mothers. While most report on increased risk of preterm delivery, data regarding other complications of pregnancy and childbirth have been equivocal [5-7].

One complication which has yet to receive ample attention in adolescents is obstetric anal sphincter injury (OASI). While being a debilitating complication of vaginal delivery, data regarding risk factors for OASI in this population are sparse. Some studies have reported on similar risk of perineal lacerations in adolescents while others have suggested young age to be a protective factor with respect to such injury $[8,9]$.

Risk factor such as operative vaginal delivery, increased birth weight, increased head circumference, prolonged second stage of labor and advanced maternal age have previously been associated with OASI but have not been thoroughly assessed in adolescents [10-13]. In addition we have previously described an association between large fetal and neonatal anthropomorphic measures and obstetric outcomes. These findings focused primarily on the large head circumference ( $\mathrm{HC}$ ) which was found associated with higher rates of interventional deliveries (cesarean, vacuum, failed vacuum, deliveries) [14-16] and higher rates of persistent occiput posterior position [17].

More recently, data has accumulated with respect to sonographic diagnosis of intrapartum sphincter tears in primiparous women showing a correlation between sonographic demonstration of tear characteristic signs and Levator Ani muscle tears [18, 19] and clinical complaints of incontinence [20].

The aim of this study was to describe risk for OASI in adolescent mothers compared to adults. We further attempted to compare risk factors for OASI between these two age groups.

\section{Methods}

We performed a retrospective cohort study at a tertiary, university, teaching medical center, between 2003 and 2019. Our cohort was comprised of primiparous women who delivered vaginally during the study period. Excluded were preterm, non-vertex, multifetal, cesarean deliveries as well as intrauterine fetal death. Institutional review board approval was received (IRB 0348-20HMO).

The study group included women following vaginal delivery up to the age of 21 . This cutoff for adolescence has been endorsed by the US department of health and the American academy of Pediatrics [21, 22]. Obstetric anal sphincter injury rate in this group was compared to occurrence of OASI in women ages 26-35. This age group was chosen as the reference group so as to distance it from younger age groups as well as older women over the age of 35 for which the process of labor may be somewhat different. Women ages 22-25 years, categorized by some as young adults, were excluded so as to eliminate any effect this special subgroup may have on the results [23]. For the purpose of assessing specific risk factors for OASI according to age, women with OASI were compared to women without such injury in each age group separately.

Data was collected from the delivery-room electronic medical records. Parameters evaluated included age, parity, comorbidities, mode of previous delivery, obstetric history, gestational week at delivery, method of labor initiation, prolonged second stage, mode of delivery, episiotomy, neonatal head circumference $(\mathrm{HC})$ and birth weight $(\mathrm{BW})$.

Laceration severity was categorized according to the American College of Obstetricians and Gynecologists practice bulletin [24]. As described by us previously, OASI was diagnosed by the most senior physician on the labor and delivery floor. Once diagnosis was established the patient was transferred to the operating room where the anal sphincter was repaired.

\section{Statistical analysis}

Comparison was performed between parturients with OASI aged $\leq 21$ and ages 26-35. In addition, in every age group, we compared those with and without OASI to identify risk factors associated with each group. Categorical variables were assessed using the Chi-square and Fischer's exact tests for small numbers, as appropriate. The t-test and Mann-Whitney $U$ tests were implemented for continuous variables. Following univariate analysis, for each age group a multivariate analysis using logistic regression was performed. We report adjusted odds ratios (aOR), 95\% confidence interval (CI) for parameters included in the final multivariate analysis. Analyses were two-tailed and $p$-values of $<0.05$ were considered significant. Statistical analysis in this study was performed using Office Excel 2010 (Microsoft, Seattle, WA) and IBM SPSS 27 for Windows (IBM corp. Armonk, NY).

\section{Results}

During the study period, 146,386 patients delivered in our institution and were evaluated for eligibility. 
Following implementation of the exclusion criteria, 111,594 patients with a live, singleton vaginal delivery remained. We further excluded multipara parturients and those who were 22-25 or older than 35 years $(92,636)$, focusing on women 21 years and under (adolescent group) and women 26-35 years of age (adult group) (Fig. 1). Finally, 5113 nulliparous adolescents and 13,845 women in the control group were included in the analysis. Allocation to study groups was according to OASI - Sixty-seven adolescents (1.3\%) had a 3rd or 4th degree perineal tear and were defined as the OASI group, while 5046 patients $(98.7 \%)$ did not have such a tear i.e. "no OASI" group. In the adult group, 199 out of 13,845 patients (1.4\%) were diagnosed with OASI (Fig. 1). The occurrence of OASI did not differ between age groups $(p=0.510)$.

Table 1 presents the comparison of obstetric and labor related characteristics of patients with obstetric anal sphincter injury (OASI) comparing the adolescents $(n=$ $67)$ to the adult age group $(n=212)$. The only parameters that differed significantly between adolescent and adult groups were rates of operative vaginal delivery (20.9\% vs. $36.2 \%$, respectively; $p=0.023)$ and meconiumstained amniotic fluid $(9.1 \%$ vs. $21.3 \%$, respectively; $p=$ 0.027).

We further focused on each age group - adolescents and adults comparing patients with and without OASI in each age group. The descriptive analysis of the

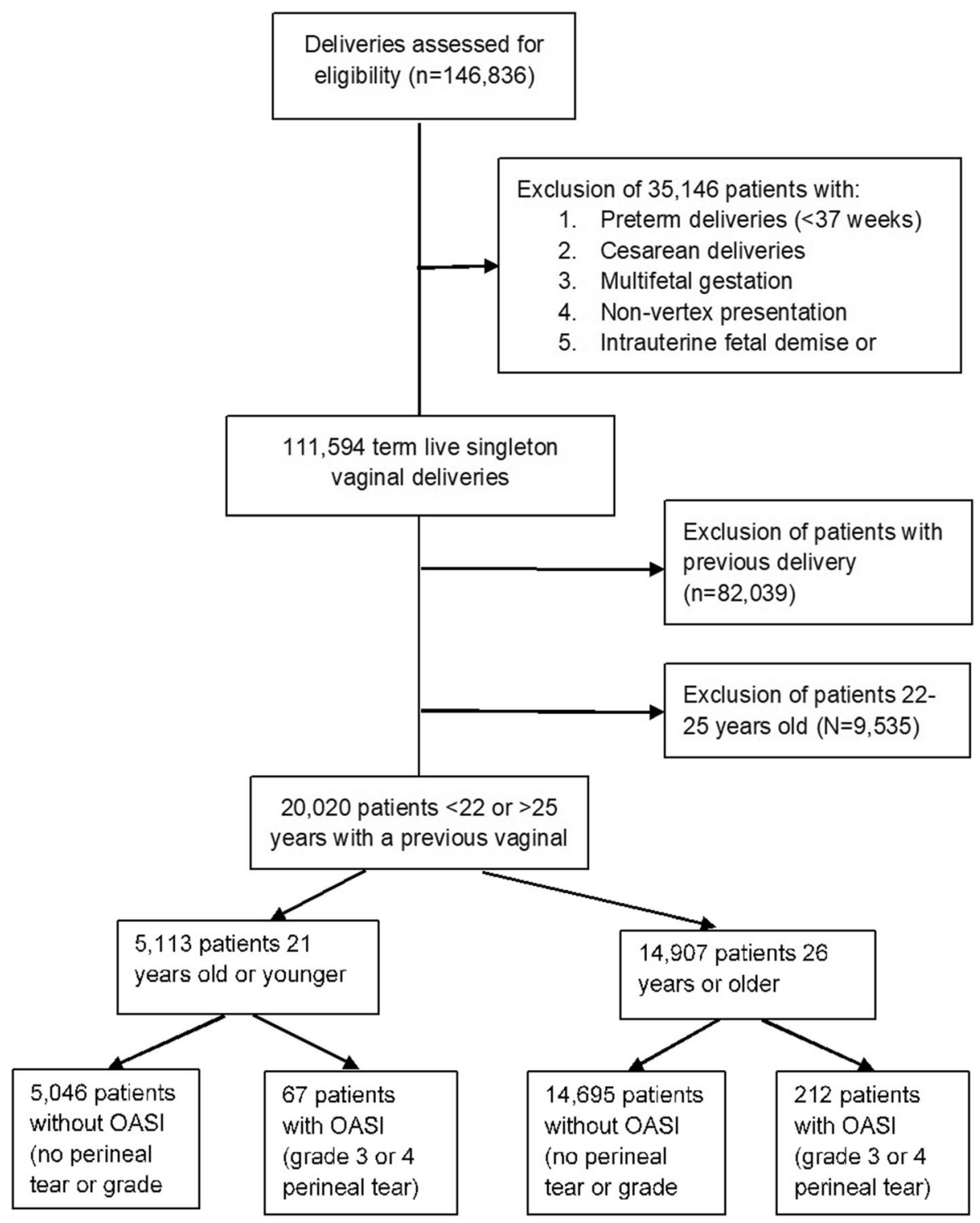

Fig. 1 Study population flow chart 
Table 1 Obstetric and labor related characteristics of patients with obstetric anal sphincter injury (OASI) according to age groups

\begin{tabular}{|c|c|c|c|}
\hline Parameter & $\leq 21$ years & 26-35 years & $P$ value $^{\mathrm{a}}$ \\
\hline No. of patients & 67 & 199 & \\
\hline Gestational diabetes & 0 & $6(3.0 \%)$ & 0.342 \\
\hline PIH/Preeclampsia & $2(3.0 \%)$ & 0 & 0.063 \\
\hline Gestational week & $39.8 \pm 1.1(40)$ & $39.7 \pm 1.1(40)$ & 0.386 \\
\hline Induction of labor & $15(22.4 \%)$ & $59(29.6 \%)$ & 0.274 \\
\hline Epidural analgesia & $46(69.7 \%)$ & $151(76.3 \%)$ & 0.328 \\
\hline Artificial rupture of membranes & 29/58 (50.0\%) & $85 / 172(49.4 \%)$ & 1.000 \\
\hline Meconium stained amniotic fluid & $6(9.1 \%)$ & $42(21.3 \%)$ & 0.027 \\
\hline Prolonged 2nd stage & $14(20.9 \%)$ & $50 / 194(25.1 \%)$ & 0.511 \\
\hline Operative vaginal delivery & $14(20.9 \%)$ & $72(36.2 \%)$ & 0.023 \\
\hline Birth weight (grams) & $3385 \pm 421(3406)$ & $3381 \pm 413(3386)$ & 0.950 \\
\hline Birth weight $>90$ th percentile $(>3900 \mathrm{~g})$ & $5(7.5 \%)$ & $19(9.5 \%)$ & 0.806 \\
\hline Head circumference $(\mathrm{cm})^{b}$ & $34.5 \pm 1.4(34.3)$ & $34.6 \pm 1.2(34.5)$ & 0.846 \\
\hline Head circumference $>90$ th percentile $(>36 \mathrm{~cm})^{b}$ & $12 / 51(23.5 \%)$ & $23 / 139(16.5 \%)$ & 0.294 \\
\hline Episiotomy & $18(26.9 \%)$ & 67 (33.7\%) & 0.364 \\
\hline
\end{tabular}

Data presented as mean \pm SD (median) or $\mathrm{n}(\%)$ or $\mathrm{n} / \mathrm{N}(\%)$

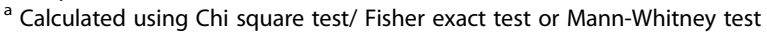

${ }^{b}$ Electronic records available since 2010 for 51 in the adolescent group and for 149 in the 26-35 age group

adolescent and the adult group population according to OASI is presented in Table 2. In the adolescent age group, no differences were noted upon comparison of rates of induction of labor ( $22.4 \%$ vs. $15.3 \%$, respectively; $p=0.079)$, epidural analgesia $(69.7 \%$ vs. $64.5 \%$, respectively; $p=0.438)$, artificial rupture of membranes $(50.0 \%$ vs. $54.2 \%$, respectively; $p=0.596$ ), prolonged second stage of labor $(20.9 \%$ vs. $14.4 \%$, respectively; $p=0.160)$ and operative vaginal delivery $(20.9 \%$ vs. $15.2 \%$, respectively; $p=0.23$ ). Evaluation of neonatal parameters in the OASI vs. no OASI groups demonstrated higher BW $(3385 \pm 421$ vs. $3321 \pm 397 \mathrm{~g}$, respectively; $p=0.001)$, larger $\mathrm{HC}(34.5 \pm 1.4$ vs. $34.2 \pm 1.2 \mathrm{~cm}$, respectively; $p=$ 0.047 ) and increased rate of $\mathrm{HC}$ above 90th percentile $(24.1 \%$ vs. $9.1 \%$, respectively; $p=0.002)$ in the OASI group.

In the adult group, higher rates of induction of labor and operative vaginal delivery were demonstrated in the OASI vs. no OASI group $(29.6 \%$ vs. 22.7 and $36.2 \%$ vs. $22.3 \%, p=0.025$ and $p<0.001$; respectively). Neonatal characteristics - higher mean neonatal $\mathrm{BW}$ and $\mathrm{HC}$ as well as the rates of neonates with larger than 90th percentile $\mathrm{HC}$ and $\mathrm{BW}$ were also shown in the OASI group (Table 2). Finally, women with OASI had more episiotomies than those without OASI (33.7\% vs. $24.9 \%$, respectively; $p=0.006$ ).

Multivariate regression models were applied to identify factors associated with OASI for the adolescent and adult groups separately (Table 3 ). The model included age, prolonged second stage of labor, operative vaginal delivery, BW above 90th percentile and HC above 90th percentile. In the adolescents' model, the analysis showed that the only parameter independently associated with OASI in the adolescent age group was $\mathrm{HC} \geq$ 90th percentile with an adjusted odds ratio of 3.08 (CI $1.48-6.38, p=0.003$ ).

In the adults group model, the analysis revealed operative vaginal delivery $(\mathrm{aOR}=2.44, \mathrm{CI} 1.72-3.47, p<0.001)$ and $\mathrm{BW} \geq 90$ th percentile $(\mathrm{aOR}=2.23$, CI $1.19-4.18, p=$ 0.012 ) to be independent risk factors for OASI.

Adolescent $\mathrm{HC}(\mathrm{cm})$ categories in the OASI vs. no OASI groups are presented in Fig. 2. Head circumference categories of under $32 \mathrm{~cm}, 32-33 \mathrm{~cm}$ and $34-35 \mathrm{~cm}$ were similar in both groups, while in the category of $\mathrm{HC}$ $\geq 36 \mathrm{~cm}$ a significant difference was noted, with a rate of $23.1 \%$ in the OASI group vs. $9.0 \%$ in the group of adolescents with no OASI $(p=0.001)$

\section{Discussion}

This study focuses on OASI in adolescents attempting to describe the unique characteristics of this important group. We found similar rates of OASI between adolescent parturiets and the adult group. Comparison between the groups revealed adolescents underwent substantially lower rate of operative vaginal delivery. We further found increased $\mathrm{BW}$, increased $\mathrm{HC}$ and $\mathrm{HC} \geq$ 90th percentile to be risk factors for OASI within this subgroup. Following logistic regression, only $\mathrm{HC} \geq 90$ th percentile was found to be an independent risk factor for OASI. In the adult group risk factors for OASI included operative vaginal delivery and BW $\geq 90$ th percentile. 
Table 2 Obstetric and labor related characteristics of patients with and without obstetric anal sphincter injury (OASI) according to age groups

\begin{tabular}{|c|c|c|c|c|c|c|}
\hline \multirow[b]{2}{*}{ Parameter } & \multicolumn{3}{|l|}{$\leq 21$ years } & \multicolumn{3}{|l|}{$26-35$ years } \\
\hline & $\overline{\text { OASI }}$ & No OASI & $\begin{array}{l}P \\
\text { value }^{\mathrm{a}}\end{array}$ & OASI & No OASI & $\begin{array}{l}P \\
\text { value }^{a}\end{array}$ \\
\hline No. of patients & $67(1.3 \%)$ & $5046(98.7 \%)$ & & $199(1.7 \%)$ & $13,646(98.3 \%)$ & \\
\hline Age & $20.2 \pm 1.0(21.0)$ & $20.3 \pm 1.0(20.6)$ & 0.780 & $28.8 \pm 2.3(28.0)$ & $29.2 \pm 1.2(29.0)$ & 0.008 \\
\hline Gestational diabetes & 0 & $32(0.6 \%)$ & 1.000 & $6(3.0 \%)$ & $263(1.9 \%)$ & 0.289 \\
\hline PIH/Preeclampsia & $2(3.0 \%)$ & $5 / 4342(1.2 \%)$ & 0.198 & 0 & $107 / 11662(1.2 \%)$ & 0.430 \\
\hline Gestational week & $39.8 \pm 1.1(40)$ & $39.6 \pm 1.2(40)$ & 0.079 & $39.7 \pm 1.2(40)$ & $39.7 \pm 1.1(40)$ & 0.007 \\
\hline Induction of labor & $15(22.4 \%)$ & $769(15.3 \%)$ & 0.082 & $59(29.6 \%)$ & $3089(22.7 \%)$ & 0.025 \\
\hline Epidural analgesia & $46(69.7 \%)$ & $3258(64.5 \%)$ & 0.438 & $151(76.3 \%)$ & $10,358(75.9 \% \%)$ & 0.994 \\
\hline Artificial rupture of membranes & 29/58 (50.0\%) & $\begin{array}{l}2190 / \\
4042(54.2 \%)\end{array}$ & 0.596 & 85/172 (49.4\%) & $\begin{array}{l}5319 / \\
11,074(48.0 \%)\end{array}$ & 0.759 \\
\hline Meconium stained amniotic fluid & $6(9.1 \%)$ & $758 / 4860(15.6 \%)$ & 0.172 & $42(21.3 \%)$ & $2496(18.9 \%)$ & 0.412 \\
\hline Prolonged 2nd stage & $14(20.9 \%)$ & 714/4947 (14.4\%) & 0.160 & $50(25.8 \%)$ & $2847(21.3 \%)$ & 0.132 \\
\hline Operative vaginal delivery & $14(20.9 \%)$ & $769(15.2 \%)$ & 0.229 & $72(36.2 \%)$ & $3044(22.3 \%)$ & $<0.001$ \\
\hline Birth weight (grams) & $\begin{array}{l}3385 \pm 421 \\
(3406)\end{array}$ & $\begin{array}{l}3321 \pm 397 \\
(3214)\end{array}$ & 0.001 & $\begin{array}{l}3382 \pm 413 \\
(3386)\end{array}$ & $3205 \pm 395(3190)$ & $<0.001$ \\
\hline Birth weight $>90$ th percentile $(>3900 \mathrm{~g})$ & $5(7.5 \%)$ & $240(4.7 \%)$ & 0.252 & $19(9.5 \%)$ & $603(4.4 \%)$ & 0.003 \\
\hline Head circumference $(\mathbf{c m})^{b}$ & $34.5 \pm 1.4(34.3)$ & $34.2 \pm 1.2(34.0)$ & 0.047 & $34.6 \pm 1.2(34.5)$ & $34.3 \pm 1.2(34.3)$ & 0.007 \\
\hline $\begin{array}{l}\text { Head circumference }>90 \text { th percentile }(>36 \\
\mathrm{cm})^{\mathrm{b}}\end{array}$ & $12 / 51(24.1 \%)$ & $210 / 2317(9.1 \%)$ & 0.002 & 23/139 (16.5\%) & 733/7138 (10.3\%) & 0.024 \\
\hline Episiotomy & $18(26.9 \%)$ & $\begin{array}{l}1245 / \\
4340(28.7 \%)\end{array}$ & 0.892 & $67(33.7 \%)$ & $2908(24.9 \%)$ & 0.006 \\
\hline
\end{tabular}

Data presented as mean \pm SD (median) or $\mathrm{n}(\%)$ or $\mathrm{n} / \mathrm{N}(\%) .{ }^{a}$ Calculated using Chi square test/ Fisher exact test or Mann-Whitney test. ${ }^{\mathrm{b}}$ Electronic records available since 2010 for 51 in OASI group and for 2317 in the remaining cohort

Previous studies have described risk of OASI in adolescents. Landy et al. analyzed 87,267 deliveries finding OASI rate in women over the age of 25 to be increased compared to women under the age of $25(\mathrm{OR}=1.6)$ [25]. In another large cohort, Torvie et al. presented data regarding 26,091 nulliparous adolescents and young adults. They found teens aged 15-19 years had decreased risk of OASI compared to young adults ages 20-24 [26].

A previous analysis performed by us was based on data available from the Consortium on Safe Labor (CSL) database, which included detailed demographic, obstetric and neonatal information from medical records of 228,562 deliveries from 19 hospitals across the U.S. This study evaluated data from 4 MedStar Health hospitals which were considered 1 of 19 medical centers in the
CSL and included 203 young adolescents (15 years or younger) and 5753 adolescents (16-21 years) who were compared to the reference group of women ages 22-34. Teenage mothers were $50 \%$ less likely to have OASI compared to the control group (adjusted OR $=0.480, \mathrm{CI}$ $0.320-0.720$ ) [27]. In our current study we found a similar rate of OASI in adolescent and adult groups. The differences between our results and the results of the studies mentioned may be explained by the low rate of OASI in our cohort. In a population with lower disposition for OASI, differences between age groups may be less prominent. In addition, the population and the comparison groups differed between studies. For instance, study population of the Consortium on Safe Labor database consisted of a higher proportion of young

Table 3 Multivariate analysis of parameters associated with obstetric anal sphincter injury

\begin{tabular}{|c|c|c|c|c|}
\hline \multirow[t]{2}{*}{ Parameter } & OR $(95 \% \mathrm{Cl})$ & $P$ value & OR $(95 \% \mathrm{Cl})$ & $P$ value \\
\hline & \multicolumn{2}{|l|}{$\leq 21$ years } & \multicolumn{2}{|l|}{ 26-35 years } \\
\hline Age & $0.90(0.69-1.19)$ & 0.461 & $0.92(0.85-0.99)$ & 0.018 \\
\hline Prolonged second stage of labor & $0.79(0.40-1.59)$ & 0.514 & $0.79(0.40-1.59)$ & 0.514 \\
\hline Operative vaginal delivery & $1.41(0.72-2.78)$ & 0.316 & $2.44(1.72-3.47)$ & $<0.001$ \\
\hline Birth weight $>90$ th percentile & $0.90(0.29-2.80)$ & 0.853 & $2.23(1.19-4.18)$ & 0.012 \\
\hline Head circumference $>90$ th percentile & $3.08(1.48-6.38)$ & 0.003 & $1.27(0.76-2.12)$ & 0.354 \\
\hline
\end{tabular}




\section{Head circumference in adolescents with and without obstetric anal sphincter injury}

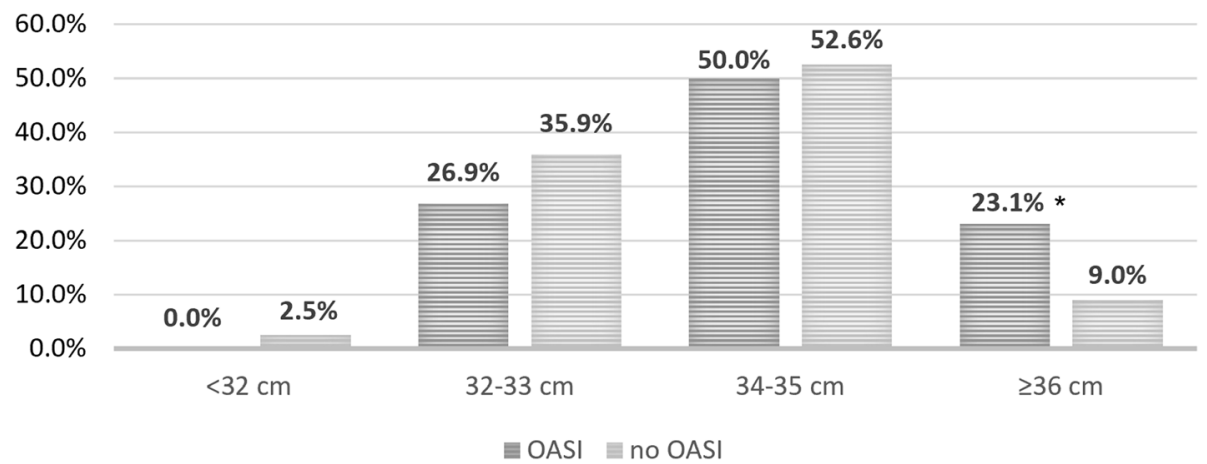

Fig. 2 Neonatal head circumference categories in laboring adolescents according to obstetric anal sphincter injury occurrence. Note: OASI, obstetric anal sphincter injury, $p=0.001^{*}$

adolescents (age 15-19), which may have an impact on OASI rate.

Our findings are in accordance with previous studies showcasing most of the known risk factors for OASI discussed in current literature [10-13]. With that, our findings point towards certain differences between the risk factors of adolescents and adults. We found neonatal as opposed to obstetric characteristics to affect risk for OASI in adolescents. Following multivariate analysis, $\mathrm{HC} \geq 90$ th percentile was the sole independent risk factor for OASI in this subgroup. Other previously proven risk factors for OASI such as operative vaginal delivery did not increase risk for OASI in our study, though it may be attributed to the relatively small study group of adolescents with OASI. In contrast, independent risk factors for the adult group included operative vaginal delivery and $\mathrm{BW} \geq 90$ th percentile. One hypothesis could be that the adolescent perineum may have different elastic properties compared to older women. These properties may affect the tissue's ability to adapt and stretch when confronted with the forces of labor. In this scenario increased $\mathrm{HC}$ stretching the perineum may have a detrimental effect on anal sphincter integrity. Another possible explanation for the significant impact of large $\mathrm{HC}$ on OASI in adolescents may be that a certain proportion of adolescent mothers have not yet completed their growth. Smaller pelvic diameters may explain the higher susceptibility of adolescent mothers to large HC. This hypothesis remains unsupported as we do not routinely collect pelvimetry data.

Limitations of this study include its retrospective design, the relatively small study group and partially missing data for certain parameters within the cohort. With that being we present one of the largest cohorts to focus on OASI in adolescents.
Data regarding functional outcome following OASI were unavailable. The statistical analysis done for a relatively large number of parameters carries the risk of false positive results due to multiple comparisons.

Few women included were in their teens limiting our ability to assess risk factors in young adolescents.

\section{Conclusion}

In summary we found adolescents have similar risk for OASI compared to older women but differ in risk factors leading to OASI. While $\mathrm{HC} \geq 90$ th percentile was found to be an independent risk factor for such injury other known risk factors for OASI were not found to be significant. Gaining a better understanding of the risk factors and mechanisms of severe perineal lacerations in this subgroup may lead to better clinical care and improved patient outcomes in the future.

\section{Abbreviations \\ OASI: Obstetric anal sphincter injury; HC: head circumference; BW: birth weight}

\section{Acknowledgments}

Not applicable.

\section{Authors' contributions}

Contribution of authors was as follows: HHC contributed to project development, data analysis, manuscript writing and editing; ML performed statistical analysis, data analysis and assisted in manuscript writing and editing; EA was influential in data collection and manuscript editing; TS assisted in data collection and manuscript editing; DS helped in data analysis and manuscript editing; GK contributed to project development, data analysis, manuscript writing and editing. All authors have read and have approved the final version of the manuscript.

\section{Funding}

No funding was received for this study.

Availability of data and materials

The datasets used and/or analyzed during the current study are available from the corresponding author on reasonable request. 


\section{Declarations}

\section{Ethics approval and consent to participate}

The study was approved by the institutional ethical review board of Hadassah Medical Center, IRB\#0348-20-HMO. All methods were performed in accordance with the relevant guidelines and regulations of the institutional ethical review board and in accordance with the Declaration of Helsinki. Informed consent was not required following a waiver granted from the institutional ethical review board.

\section{Consent for publication}

Not applicable.

\section{Competing interests}

The authors declare that they have no competing interests.

Received: 24 April 2021 Accepted: 10 August 2021

Published online: 18 August 2021

\section{References}

1. Chandra PC, Schiavello HJ, Ravi B, et al. Pregnancy outcomes in urban teenagers. Int J Gynaecol Obstet. 2002;79:117-22.

2. Stewart CP, Katz J, Khatry SK, et al. Preterm delivery but not intrauterine growth restriction is associated with young maternal age among primiparae in rural Nepal. Matern Child Nutr. 2007:3(3):174-85.

3. Hamilton BE, Martin JA, Osterman MJK, et al. Births: final data for 2014. Nat Vital Stat Rep. 2015;64(12):1-64

4. McCarthy FP, O'Brien $U$, Kenny $L C$. The management of teenage pregnancy. BMJ. 2014:349:95887.

5. Perry RL, Mannino B, Hediger ML, Scholl TO. Pregnancy in early adolescence: are there obstetric risks? J Matern Fetal Med. 1996;5(6):333-9.

6. Azevedo WF, Diniz MB, Fonseca ES, Azevedo LM, Evangelista CB. Complications in adolescent pregnancy:systematic review of the literature. Einstein (Sao Paulo). 2015;13(4):618-26.

7. Kawakita T, Wilson K, Grantz KL, et al. Adverse maternal and neonatal outcomes in adolescent pregnancy. J Pediatr Adolesc Gynecol. 2016;29(2): 130-6.

8. Patterson D, Hundley AF. Risk factors for perineal lacerations in teen deliveries. Female Pelvic Med Reconstr Surg. 2010;16(6):345-8.

9. Aviram A, Raban O, Melamed N, et al. The association between young maternal age and pregnancy outcome. J Matern Fetal Neonatal Med. 2013; 26(15):1554-8

10. Ott J, Gritsch E, Pils S, et al. A retrospective study on perineal lacerations in vaginal delivery and the individual performance of experienced midwives BMC Pregnancy Childbirth. 2015:15:270

11. Low LK, Zielinski R, Tao Y, Galecki A, Brandon CJ, Miller JM. Predicting birthrelated levator ani tear severity in primiparous women: evaluating maternal recovery from labor and delivery (EMRLD study). Open J Obstet Gynecol. 2014:4:266-78.

12. Andrews V, Sultan AH, Thakar R, Jones PW. Risk factors for obstetric anal sphincter injury: a prospective study. Birth. 2006;33:117-22.

13. Baghestan E, Irgens LM, Bordahl PE, Rasmussen S. Trends in risk factors for obstetric anal sphincter injuries in Norway. Obstet Gynecol. 2010;116:25-34.

14. Lipschuetz M, Cohen SM, Ein-Mor E, et al. A large head circumference is more strongly associated with unplanned cesarean or instrumental delivery and neonatal complications than high birthweight. Am J Obstet Gynecol. 2015;213(6):833. e831-833 e812

15. Lipschuetz M, Cohen SM, Israel A, et al. Sonographic large fetal head circumference and risk of cesarean delivery. Am J Obstet Gynecol. 2018; 218(3):339. e331-339 e337.

16. Kabiri $\mathrm{D}$, Lipschuetz $\mathrm{M}$, Cohen $\mathrm{SM}$, et al. Vacuum extraction failure is associated with a large head circumference. J Matern Fetal Neonatal Med. 2019;32(20):3325-30

17. Yagel $\mathrm{O}$, Cohen SM, Lipschuetz $\mathrm{M}$, et al. Higher rates of operative delivery and maternal and neonatal complications in persistent occiput posterior position with a large head circumference: a retrospective cohort study. Fetal Diagn Ther. 2018;44(1):51-8.

18. Lipschuetz M, Valsky DV, Shick-Naveh L, et al. Sonographic finding of postpartum levator ani muscle injury correlates with pelvic floor clinical examination. Ultrasound Obstet Gynecol. 2014;44(6):700-3.
19. Valsky DV, Lipschuetz M, Cohen SM, et al. Persistence of levator ani sonographic defect detected by three-dimensional transperineal sonography in primiparous women. Ultrasound Obstet Gynecol. 2015;46(6): 724-9.

20. Valsky DV, Cohen SM, Lipschuetz M, Hochner-Celnikier D, Yagel S. Threedimensional transperineal ultrasound findings associated with anal incontinence after intrapartum sphincter tears in primiparous women. Ultrasound Obstet Gynecol. 2012;39(1):83-90.

21. US Department of Health and Human Services Food and Drug Administration. Guidance for Industry and FDA Staff: Pediatric Expertise for Advisory Panels. Rockville, MD: US Department of Health and Human Services, Food and Drug Administration, Center for Devices and Radiological Health; 2003. Available at: www.fda.gov/downloads/Medica IDevices/DeviceRegulationandGuidance/GuidanceDocuments/ucm082188. pdf. Accessed 15 Mar 2021

22. Hagan JF Jr, Shaw JS, Duncan P, editors. Bright futures: guidelines for the health supervision of infants, children, and adolescents. 3rd ed. Elk Grove Village: American Academy of Pediatrics; 2008.

23. Society for Adolescent Health and Medicine. Young Adult Health and WellBeing: A Position Statement of the Society for Adolescent Health and Medicine J Adolesc Health. 2017;60(6):758-759.

24. Committee on Practice Bulletins-Obstetrics. ACOG Practice Bulletin No. 198: prevention and management of obstetric lacerations at vaginal delivery. Obstet Gynecol 2018;132(3):e87-e102.

25. Landy HJ, Laughon SK, Bailit JL, et al. For the consortium on safe labor. Characteristics associated with severe perineal and cervical lacerations during vaginal delivery. Obstet Gynecol. 2011;117:627-35.

26. Torvie AJ, Callegari LS, Schiff MA, et al: Labor and delivery outcomes among young adolescents. Am J Obstet Gynecol. 2015; 213(1):95.e1-8.

27. Shveiky D, Patchen L, Chill HH, Pehlivanova M, Landy HJ. Prevalence and location of obstetric lacerations in adolescent mothers. J Pediatr Adolesc Gynecol. 2019;32(2):135-8.

\section{Publisher's Note}

Springer Nature remains neutral with regard to jurisdictional claims in published maps and institutional affiliations.

Ready to submit your research? Choose BMC and benefit from:

- fast, convenient online submission

- thorough peer review by experienced researchers in your field

- rapid publication on acceptance

- support for research data, including large and complex data types

- gold Open Access which fosters wider collaboration and increased citations

- maximum visibility for your research: over $100 \mathrm{M}$ website views per year

At BMC, research is always in progress.

Learn more biomedcentral.com/submission 